\title{
UK Specialists' and GDPs' Use of Systemic and Local Antimicrobial Administration in Periodontal Therapy: A Questionnaire Study
}

\author{
Padtong EA ${ }^{1}$, Turner $\mathrm{W}^{1,2}$ and Gillam $\mathrm{DG}^{1 *}$ \\ ${ }^{1}$ Institute of Dentistry, Barts and the London School of Medicine and Dentistry QMUL, London, UK \\ ${ }^{2}$ Centre for Dentistry, School of Medicine, Dentistry and Biomedical Science, Queen's University Belfast, Belfast UK
}

${ }^{*}$ Corresponding Author: David Gillam, Oral Bioengineering, Institute of Dentistry, Barts and the London School of Medicine and Dentistry QMUL, London, EA1 2AD, UK; E-mail: d.g.gillam@qmul.ac.uk

Received: February 06, 2020; Accepted: February 11, 2020; Published: February 14, 2020

\begin{abstract}
Aim: The aim of the present study was to evaluate the use of antimicrobials, the prescription patterns and the reason(s) for prescribing antimicrobials when treating periodontal disease in selected UK General Dental Practitioner (GDP) and Periodontal Specialists.

Materials \& Methods: The questionnaire consisted of 21 questions and was sent to 488 Periodontal Specialists and 488 GDPs. Data management and analysis was performed using Microsoft Excel, SPSS ${ }^{\circledR}$ version 22.0 software and frequency distributions, cross tabulation tables and graphs were constructed from the data. Any association between variables was tested at the $5 \%$ level of significance $(\mathrm{P} \leq 0.05)$.

Results: The questionnaires were completed by the Specialists $(38.72 \%)(n=189)$ and $23.36 \%(n=114)$ of the GDPs. The results indicated that the use of systemic and local antimicrobials followed the current guidelines. Specialists prescribed more systemic antimicrobials than the GDPs, although Specialists limited the use of local antimicrobials. The GDPs reported that decision making was difficult when to use local antimicrobials although recognised that using local antimicrobials were more effective than root surface debridement alone. Other reasons for using antimicrobials were based either on the patient request or patient satisfaction with the treatment. Lower frequency of antimicrobial use was reported in regeneration and implant procedures by both Specialists and GDPs although the Specialists were more inclined to use antibiotics/antimicrobials in these procedures.
\end{abstract}

Conclusions: The results of the study suggested that there was a need for dentists to follow current guidelines when prescribing antibiotics/antimicrobials in order to avoid unnecessary prescriptions, antibiotic resistance and adverse drug reactions.

Keywords: Adjunctive Use, Antibiotic Prescribing, Evidence-Based Guidelines for Prescribing, Management, Periodontal Diseases

\section{Introduction}

The effectiveness of adjunctive antimicrobial or antibiotic therapy in periodontal disease and implant placement has been strongly supported in the published literature [1-3]. However other studies both in the United Kingdom (UK) and in countries outside the UK have reported that antibiotics/antimicrobials may be inappropriately prescribed and used by dental practitioners [4-11]. Several investigators have also reported on the effect on non-clinical factors such as requests or demands from patients $[8,10]$. From these studies it was evident that there is a need to not only to provide both General Dental Practitioners and Specialists with clear and concise guidelines on what and when to prescribe appropriate antimicrobials/antibiotics together with the correct dosage and duration of use but also the need to continually update their knowledge in attending continuing professional education courses and basing their prescribing habits on evidence-based clinical practice [7-8]. According to Gillam \& Turner [12] the importance of current and updated recommendations and guidelines on the appropriate use of antibiotics/antimicrobials in general dental practice cannot be underestimated. More recently several tool kits and guidance notes on dental prescribing have been made available such as the SCECP Scottish Drug Prescribing for Dentistry and the NHS England Public Health England Dental antimicrobial stewardship: toolkit. [13-14]

\section{Materials and Methods}

\section{Aims and Objectives}

The objective of present study was to evaluate the use of antimicrobials, the prescription pattern and the reason(s) for prescribing antimicrobials when treating periodontal disease in selected UK General Dental Practitioner (GDP) and Dentists who were on the Specialist list for Periodontics or who expressed an interest in Periodontics.

\section{Questionnaire Design}

The present study questionnaire was modified from Choudhury et al. [8] based on pre 1999 guidelines in order to implement the 
changes in the American Academy of periodontology (AAP) [1516] classification and was assessed by the Queen Mary University of London (QMUL) Research Ethics Committee (QMREC1047) with the conclusion that no ethical concerns were present and the proposed study was considered to be of an "extremely low risk". The questionnaire consisted of 20 questions which were mainly closed questions. Questions 1-4 requested the demographic data by identifying the age, gender, the years since graduation, and the type of practice. Question 5 requested information in relation to the amount of time allocated by the participants for root surface debridement for each quadrant and whether any local anaesthesia was used. Question 6 related to a question whether the participants prescribed local or systemic antimicrobials for periodontal conditions. Questions 7-11 attempted to determine the indications of use of the antimicrobial in periodontal diseases, and Questions 12-18 aimed to gain information about decision making in the choice of local/systemic antimicrobials in treating periodontal conditions, rationale for use or not using and whether the treatment was success/unsuccessful. Questions 1920 determined to obtain the information of attendance on courses on antimicrobials in periodontal therapy, as well as information on whether the respondent was a Member of a Specialist Society. The questionnaire consisted of four A4 pages. An introductory letter for participants was sent with each questionnaire together with a stamped address or prepaid envelope for those participants responding by the postal service (Royal Mail).

A pilot study using a cross-sectional self-administered questionnaire preceded the main survey in April 2013, during which time 100 questionnaires were given to dentists of different clinical disciplines. The participants were either staff members or postgraduate students working or studying in the Centre for Adult Oral Health at the Bart's and The London School of Medicine and Dentistry, QMUL, London UK. The pilot study lasted for approximately 3 months (January to March 2013). The initial analysis of the pilot data enabled the investigators to check whether any clarification of the questions or improvement final layout of the questionnaire was required prior to distribution to practicing dentists on the GDC Specialist List or the General Dental Practice List. The selection of the practices for the present study was based on the available lists of Dentists from either the Specialist of Periodontics List or selected General Dental Practitioners (GDP) on the General Dental Council (GDC) Register respectively. The final version of the cross-sectional selfadministered postal questionnaire survey was completed following very minor administrative revisions such as typographic errors prior to distribution. The practitioners on the Specialist list (388) were sent a questionnaire by Roy Iail. (A further 100 questionnaires were also distributed by EA: - a a British Society of Periodontology (BSP) in April 2013-Conference in Manchester UK; and a randomized matched sample using addresses of General Dental Practitioners (GDP) on the GDC Register (488) were generated using a randomised number generator (RNG) (GraphPad Software Inc. 2002-2005). Due to time constraints a four-month period was allowed for to enable the participants to respond, no subsequent reminders were sent for those who did not response within this period. All completed questionnaires returned within the four-month period were included in the final analysis.

\section{Statistical analysis}

Data management and analysis was performed using both Microsoft Excel (Microsoft Office 2010) and SPSS (version 22.0 software, IBM, Portsmouth UK) and Microsoft word 2010. Frequency distributions and cross tabulation tables were constructed and graphs for this data were plotted using Excel and Word software. For the description of median, standard deviations, minimum and maximum values for continuous data and frequencies and relative frequencies (proportions) for categorical data were also calculated. Statistical analysis performed on data from the returned questionnaires included both parametric and non-parametric tests and the significance level was set up at $\alpha=0.05$ (95\%). Non-parametric tests were used if the data did not follow normal distribution. For categorical data, non-parametric tests were also used (Figure 1). Analysis performed included the following:

\section{Steps of Data Analysis}

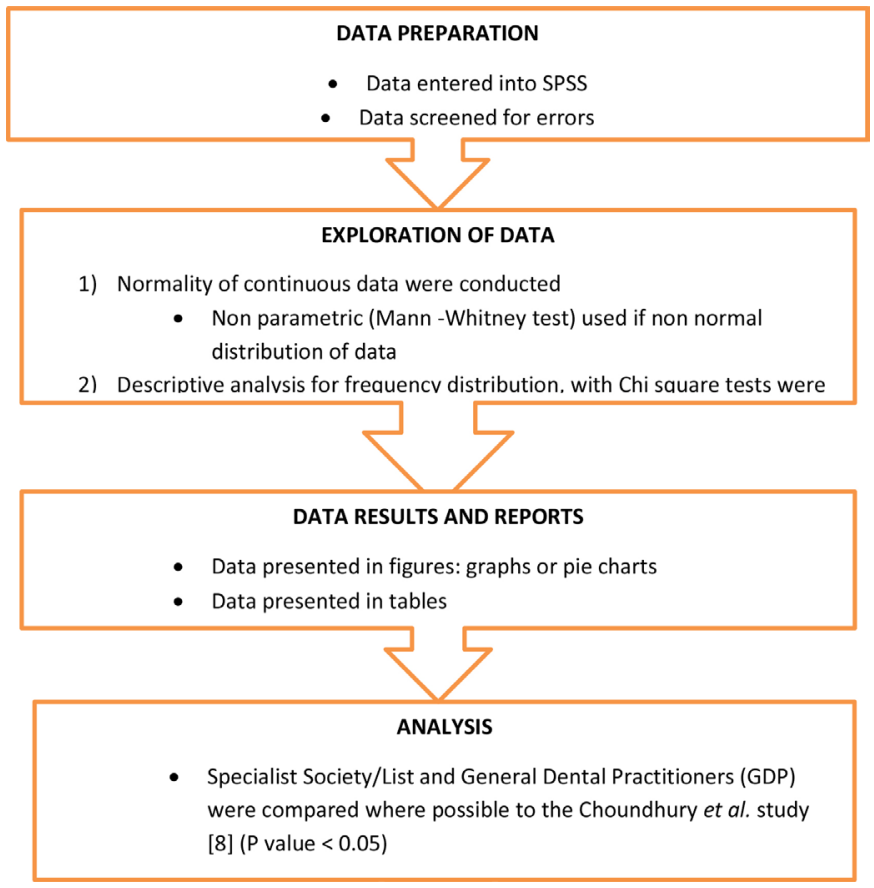

Figure 1. Flow Diagram: Steps in Data Analysis.

1. Calculation of mean values of age and years since graduation together with standard deviations

2. Estimation of frequencies of answers for each question indicating categorical data

3. A Chi-square test was performed in order to assess the association between two categorical variables, e.g. the relation of treatment chosen to the level of dentist's interest 
4. Mann-Whitney tests were performed in order to assess the association between a continuous and a categorical variable, e.g. in decision making in using systemic or local antimicrobials and the General Practitioner/Specialist Periodontist status.

Data analysis from the present study was compared, where possible, to data from the original Choudhury et al. [8] study.

\section{Results}

\section{Frequency distribution of the study participants}

350 participants: 47 (13.4\%) participants from the pilot study and from the main study 114 (32.6\%) participants from General Dental Practice and 189 (54\%) participants who were either on the Specialist List or who expressed an interest in Periodontology were included in the final analysis of the data.

\section{Characteristics of the pilot study participants}

The pilot study population included dentists of different clinical disciplines who were either staff members or the postgraduate working or studying in the Centre for Adult Oral Health at the Bart's and The London School of Medicine and Dentistry, QMUL, London United Kingdom, the sample population $(\mathrm{n}=47)$ was investigated. 100 questionnaires were handed out to the Dentists, and 57 questionnaires were returned (57\%), of which 10 were incomplete or indicated as being not applicable to the individuals' practice. In total 47 (47\%) of the returned questionnaires were entered into the data set.

\section{Demographic characteristics of the main study participants}

The main study population included the Specialists $(n=189)$ and GDPs $(n=114)$ in the United Kingdom. A total sample population $(\mathrm{n}=303)$ was included in the main study.

\section{Frequency distribution of the questionnaires of the main study population}

In total 488 questionnaires sent out to the GDPs, and 119 questionnaires were returned $(24.39 \%)$, of which 114 were usable $(23.36 \%)$ and entered into the data base (Five participants reported that they had either, retired or that the questionnaire was not applicable to their practice).

The distribution of the questionnaire was in two parts: 1) 388 questionnaires were sent out to the Specialists in the Specialist list, and 109 were returned of which 98 were entered (11 questionnaires were either incomplete or not applicable to the individuals' practice); 2) 100 questionnaires were handed out by EAP to the Specialists attending a British Society Meeting (BSP) in Manchester. Ninetyone (91) questionnaires were returned and completed. In total, 200 questionnaires (40.98\%) were returned, and 189 (38.72\%) were entered into the data set.

\section{Age and years of graduation of the main study population}

The mean age of the 245 participants was 44.8 years (SD +/-11.96 years; age range 23-70 years, missing value 58 ). The mean years from graduation was 21.04 years ( $\mathrm{SD}+/-11.6$ years; $n=302$, one missing value, range $1-48$ years).

\section{Gender distribution of the main study population of the GDPs and Specialists in the United Kingdom}

The gender distribution of the main study population of the GDPs and Specialists were reported namely M:111/189 (58.73\%); F:78/189 (41.27\%) in the Specialist Group and M: 80/114 (70.18\%); F 34/114 $(29.82 \%)$ in the GDP Group. The Specialist members therefore significantly comprised more females $41.27 \%(n=78)$ whereas the GDPs population comprised more males $70.18 \% \%(n=80)(p=0.046)$.

\section{Specialist membership in the main study population}

85.56\% (160, two missing value) were Specialist members whereas $14.91 \%$ ( $n=17)$ were GDPs. $85.09 \%$ ( $n=97)$ GDPs were not on a Specialist list. $14.44 \%(\mathrm{n}=27)$ of participants who were Specialists reported that they did not have Specialist membership. Regarding the British Society Periodontology membership, $80 \%$ (148, four missing value) of specialist participants reported that they were members of the BSP and only $4.39 \%(n=5)$ of the GDPs were BSP members. Of those who were not members of the BSP $20 \%(n=37)$ were Specialists and $95.61 \%(n=109)$ were GDPs.

\section{Lecture or course attended in systemic or local antimicrobial in periodontal therapy}

A clear difference between the Specialist and GDP participants was observed when the participants were asked about their attendance on periodontal therapy lectures or courses in systemic and local antimicrobial therapy. There was a higher number of Specialist participants attending systemic [89.73\% ( $n=166$, six missing value)] or local antimicrobials in periodontal therapy, [76.50 \% ( $\mathrm{n}=140$, six missing value)] compared to the GDP response [49.56 \% $(n=56$, one missing value for systemic courses and $42.98 \%(n=49$, one missing value attending local delivery courses ( $\mathrm{p}=0.0005$ for both systemic and local delivery). One Specialist participant indicated that they gave a lecture on both systemic and local antimicrobial therapy in periodontal therapy.

\section{Periodontal management}

Duration allocated for root surface debridement (RSD) of an involved quadrant of 6-7 teeth of the main study population of the GDPs and Specialists in the United Kingdom

In relation to the allocation time for root surface debridement (RSD) duration of an involved quadrant of 6-7 teeth, GDPs tend to spend less time in RSD $51.33 \%(n=58)$ which was only up to 30 minutes. Whereas $27.03 \%(\mathrm{n}=50)$ Specialist participants and $6.19 \%$ $(n=7)$ GDPs allocated up to 60 minutes for a quadrant. None of the GDPs reported spend more than 60 minutes for RSD whereas only $2.70 \%(n=5)$ of Specialists reported that they spent more than 60 minutes (Table 1). 
Table 1. Duration allocated for root surface debridement (RSD) of an involved quadrant of 6-7 teeth of the main study population of the GDPs $(n=113)$ and Specialists $(n=185)$ in the United Kingdom.

\begin{tabular}{|l|c|c|c|}
\hline \multicolumn{1}{|c|}{ Item } & $\begin{array}{c}\text { Specialist society/list } \\
\mathbf{N}(\%)\end{array}$ & $\begin{array}{c}\text { GDP } \\
\mathbf{N}(\%)\end{array}$ & \multirow{2}{*}{ P value } \\
\hline $\begin{array}{l}\text { Up to } 30 \\
\text { minutes }\end{array}$ & $45 / 185(24.32)$ & $\begin{array}{c}58 / 113 \\
(51.33)\end{array}$ & \multirow{2}{*}{0.0005} \\
\hline $\begin{array}{l}\text { Up to } 60 \\
\text { minutes }\end{array}$ & $50 / 185(27.03)$ & $7 / 113(6.19)$ & \\
\hline$>60$ minutes & $5 / 185(2.70)$ & $0 / 113(0.00)$ & \\
\hline
\end{tabular}

\section{Frequency of participants routinely administer local} anaesthetic (LA) for RSD procedure of the main study population of the GDPs and Specialists in the United Kingdom

When asked whether they would routinely administer a local anaesthetic (LA) for RSD procedures a higher number of Specialist participants $88.77 \%$ ( $n=166$, two missing value) indicated that would tend to administer LA for RSD procedures compared to GDPs $62.39 \%$ $(\mathrm{n}=68$, five missing value $)(\mathrm{p}=0.0005)$.

\section{Frequency of the type of periodontal disease treated}

(2) 2) Specialists 100\% (n=188) and GDPs $100 \%(n=114)$ had observed patients with chronic periodontitis in their clinic. A higher number of GDPs had observed gingivitis cases $99.10 \%$ ( $\equiv$ 09) $(\mathrm{p}=0.061)$, apical periodontitis $84.90 \%(\mathrm{n}=90)$ $(\mathrm{p}=0.099)$, and $\mathrm{NUG} 93.70 \%(\mathrm{n}=104)(\mathrm{p}=0.524)$ than the Specialist members however the difference was not significant. Whereas the Specialist members had treated aggressive periodontitis $94.14 \%$ $(\mathrm{n}=177) \quad(\mathrm{p}=0.0005)$, and unresponsive sites $90.10 \% \quad(\mathrm{n}=164)$ $(\mathrm{p}=0.0005)$ more than the GDPs.

Table 2. Frequency of the classification of periodontal disease treated of the main study population of the GDPs and Specialists in the United Kingdom (Please note the various descriptive terms to describe periodontal diseases has recently been reclassified).

\begin{tabular}{|l|c|c|c|}
\hline \multicolumn{1}{|c|}{ Item } & $\begin{array}{c}\text { Specialist Society/List } \\
\mathbf{N}(\%)\end{array}$ & $\begin{array}{c}\text { GDP } \\
\mathbf{N}(\%)\end{array}$ & P value \\
\hline Gingivitis & $168 / 177(94.90)$ & $109 / 110(99.10)$ & 0.061 \\
\hline $\begin{array}{l}\text { Chronic } \\
\text { periodontitis }\end{array}$ & $188 / 188(100)$ & $114 / 114(100)$ & ns \\
\hline $\begin{array}{l}\text { Aggressive } \\
\text { periodontitis }\end{array}$ & $177 / 188(94.14)$ & $78 / 106(73.60)$ & 0.0005 \\
\hline Apical periodontitis & $139 / 181(76.80)$ & $90 / 106(84.90)$ & 0.099 \\
\hline $\begin{array}{l}\text { Necrotising } \\
\text { ulcerative gingivitis }\end{array}$ & $171 / 184(90.48)$ & $104 / 111(93.70)$ & 0.524 \\
\hline Unresponsive sites & $164 / 182(90.10)$ & $46 / 100(46.00)$ & 0.0005 \\
\hline
\end{tabular}

\section{Use of systemic and local delivery antimicrobials}

Frequency of the use of systemic and local delivery antimicrobials: In general, more Specialist Society/List members reported that they had prescribed systemic antimicrobials as compared to the GDPs, whereas the local delivery antimicrobials were more frequently used by the GDPs compared to the Specialist Society/ List members in treating the different types of periodontal diseases. Regarding the use of systemic antimicrobials, the Specialist Society/ List members would more frequently use this type of antimicrobial therapy to treat aggressive periodontitis $76.90 \%(\mathrm{n}=143, \mathrm{p}=0.0005)$, and unresponsive sites, $33.16 \%(\mathrm{n}=64)(\mathrm{p}=0.008)$. Only one $(0.57 \%)$ and $(0.93 \%)$ of the Specialists and GDP used this antimicrobial therapy in gingivitis respectively $(\mathrm{p}=0.140)$.

Regarding local antimicrobials, a small number of Specialist members $2.22 \%(n=4)$ and GDP $4.80 \% \quad(n=5)$ opted to use antimicrobial therapy in gingivitis respectively $(\mathrm{p}=0.005)$. There were no significant differences in the number of participants from both groups who opted to use local antimicrobials in chronic periodontitis, 17.43\% ( $\mathrm{n}=19)$ GDPs and Specialist members 9.44\% $(\mathrm{n}=17)(\mathrm{p}=$ 0.013 , missing value 14). There was no difference in the frequency of GDP $20.00 \%(n=17)$ who used local antimicrobials to treat sites and the Specialist members, $15.73 \%(\mathrm{n}=28) .(\mathrm{p}=0.0 .395)$ (Table 3$)$.

Table 3. Use of systemic and local delivery antimicrobials in periodontal therapy by GDPs and Specialists in the United Kingdom.

\begin{tabular}{|c|c|c|c|c|c|}
\hline \multirow[t]{2}{*}{ Item } & \multicolumn{2}{|c|}{$\begin{array}{c}\text { Specialist Society/ } \\
\text { List }\end{array}$} & \multicolumn{2}{|c|}{ GDP } & \multirow[t]{2}{*}{ P value } \\
\hline & Number & (\%) & Number & $(\%)$ & \\
\hline \multicolumn{6}{|l|}{$\begin{array}{l}\text { Use of systemic } \\
\text { antimicrobials }\end{array}$} \\
\hline $\begin{array}{l}\text { Often/routinely for } \\
\text { gingivitis }\end{array}$ & $1 / 174$ & 0.57 & $1 / 107$ & 0.93 & 0.140 \\
\hline $\begin{array}{l}\text { Often/routinely for } \\
\text { chronic periodontitis }\end{array}$ & $11 / 184$ & 5.98 & $5 / 112$ & 4.46 & 0.404 \\
\hline $\begin{array}{l}\text { Often/routinely } \\
\text { for aggressive } \\
\text { periodontitis }\end{array}$ & $143 / 186$ & 76.90 & $36 / 100$ & 36.00 & 0.0005 \\
\hline $\begin{array}{l}\text { Often/routinely for } \\
\text { apical periodontitis }\end{array}$ & $30 / 154$ & 19.50 & $32 / 101$ & 31.70 & 0.003 \\
\hline $\begin{array}{l}\text { Often/routinely for } \\
\text { necrotising ulcerative } \\
\text { gingivitis }\end{array}$ & $138 / 177$ & 77.97 & $89 / 108$ & 82.41 & 0.603 \\
\hline $\begin{array}{l}\text { Often/routinely for } \\
\text { unresponsive sites }\end{array}$ & $64 / 177$ & 33.16 & $18 / 79$ & 22.78 & 0.008 \\
\hline \multicolumn{6}{|l|}{$\begin{array}{l}\text { Use of local } \\
\text { antimicrobials }\end{array}$} \\
\hline $\begin{array}{l}\text { Often/routinely for } \\
\text { gingivitis }\end{array}$ & $4 / 180$ & 2.22 & $5 / 104$ & 4.80 & 0.005 \\
\hline $\begin{array}{l}\text { Often/routinely for } \\
\text { chronic periodontitis }\end{array}$ & $17 / 181$ & 9.39 & $19 / 109$ & 17.43 & 0.013 \\
\hline $\begin{array}{l}\text { Often/routinely } \\
\text { for aggressive } \\
\text { periodontitis }\end{array}$ & $32 / 182$ & 17.58 & $19 / 99$ & 19.19 & 0.101 \\
\hline $\begin{array}{l}\text { Often/routinely for } \\
\text { apical periodontitis }\end{array}$ & $4 / 173$ & 2.31 & $8 / 95$ & 8.42 & 0.0005 \\
\hline $\begin{array}{l}\text { Often/routinely for } \\
\text { necrotising ulcerative } \\
\text { gingivitis }\end{array}$ & $10 / 177$ & 5.65 & $20 / 103$ & 19.42 & 0.001 \\
\hline $\begin{array}{l}\text { Often/routinely for } \\
\text { unresponsive sites }\end{array}$ & $28 / 178$ & 15.73 & $17 / 85$ & 20.00 & 0.395 \\
\hline
\end{tabular}


Frequency and percentages of the Specialist Society/List vs. GDPs who prescribed antimicrobials in regenerative and implant procedure: The GDP group opted for prescribed antimicrobials in regenerative procedures $13.08 \%(\mathrm{n}=14$, nine missing value) or implant procedures $22.22 \%$ ( $n=24,9$ missing value) less frequently as compared to the specialists $(\mathrm{p}=0.0005)$. Almost half of the Specialist members prescribed antimicrobials in regenerative procedures $45.60 \%$ ( $\mathrm{n}=83,12$ missing value) or implant procedures $46.93 \%$ ( $\mathrm{n}=84,12$ missing value).

Frequency of success perceived by the Specialist and GDP participants in the use of systemic and local delivery antimicrobials (often/routinely, very successful): Systemic antimicrobials as an adjunctive treatment was perceived to be a successful treatment by $78.33 \%$ ( $\mathrm{n}=141$, missing value 56 ) of the Specialist members compared to the GDP response $[62.73 \%(n=69,27), p=0.016]$. In regard to local antimicrobials, the Specialists $25.55 \%(n=35$, missing value 56$)$ were less inclined to consider that antimicrobial therapy was successful as compared to the GDP response $32.58 \%$ ( $n=29$, missing value 27 ) however this was not significantly different, $\mathrm{p}=0.172$.

Ease in the decision-making process when using systemic antimicrobials in periodontal therapy: $97.88 \%(n=185)$ of the specialist members reported a median of 8 ( $0-10$ scale) for the ease in decision making in systemic antimicrobial therapy whereas $98.25 \%$ $(n=112)$ of the GDPs reported a median of $6(\mathrm{p}=0.0005$, missing 6$)$. Regarding the ease in the decision-making process when using local antimicrobials, $92.60 \%(\mathrm{n}=175)$ Specialist members reported a median of $8(0-10$ scale $)$ whereas $94.73 \%(n=108)$ of the GDPs reported a median of 6 ( $\mathrm{p}=0.0005$, missing 28).

Stated reasons to use or not to use local antimicrobials: Of those using local antimicrobials, 65.85\% ( $n=54)$ GDPs stated that a reason for use was the superiority of root surface debridement alone $(\mathrm{p}=0.0 .50)$ whereas $27.63 \%(\mathrm{n}=21)$ stated that the reason for use was more cost effective than any of the other options ( $p=0.333$ ). The GDPs more frequently stated several reasons for this option namely 1 ) to avoid the need for surgery $56.41 \%(\mathrm{n}=44) \mathrm{p}=0.257,2)$ patient requested the treatment $31.65 \%(\mathrm{n}=25) \mathrm{p}=0.011$, and 3$)$ patient satisfaction with treatment 53.25\% $(\mathrm{n}=41)(\mathrm{p}=0.0005)$.

In regard to the reason for not using local antimicrobials, the most commonly stated reasons were: 1 ) no need (Specialist members 74.13\% ( $\mathrm{n}=106)$, GDP $66.67 \%(\mathrm{n}=52), \mathrm{p}=0.002$, and 2$)$ the lack of supporting research data (Specialist members $74.32 \%$, GDP $55.70 \%$, $\mathrm{p}=0.001$. The lack of postgraduate training locally was also a reported discouragement for GDP $64.56 \%(\mathrm{n}=51)$ but was not for Specialist members $22.30 \%(\mathrm{n}=31), \mathrm{p}=0.0005$ (Table 4$)$.

Table 4. Stated reasons to use or not to use local antimicrobials in the main study population of the GDPs and Specialists in the United Kingdom.

\begin{tabular}{|c|c|c|c|c|c|}
\hline \multirow[t]{2}{*}{ Item } & \multicolumn{2}{|c|}{ Specialist Society/List } & \multicolumn{2}{|c|}{ GDP } & \multirow{2}{*}{ P value } \\
\hline & Number+ & $(\%)$ & Number+ & $(\%)$ & \\
\hline \multicolumn{6}{|c|}{ Stated reasons for using local antimicrobials } \\
\hline More effective than RSD alone & $66 / 129$ & 51.16 & $54 / 82$ & 65.85 & 0.050 \\
\hline More cost effective than other options & $27 / 129$ & 20.93 & $21 / 76$ & 27.63 & 0.193 \\
\hline Keen to try new treatment options & $38 / 120$ & 31.67 & $41 / 78$ & 61.20 & 0.049 \\
\hline Avoids the need for surgery & $57 / 127$ & 44.88 & $44 / 78$ & 56.41 & 0.257 \\
\hline Patient requests the treatment & $16 / 124$ & 12.90 & $25 / 79$ & 31.65 & 0.011 \\
\hline Patient satisfaction with treatment & $30 / 123$ & 24.39 & $41 / 77$ & 53.25 & 0.0005 \\
\hline \multicolumn{6}{|l|}{$\begin{array}{l}\text { Stated reasons for not using local } \\
\text { antimicrobials }\end{array}$} \\
\hline Cost & $52 / 143$ & 36.36 & $39 / 83$ & 46.99 & 0.271 \\
\hline No need & $106 / 143$ & 74.13 & $52 / 78$ & 66.67 & 0.002 \\
\hline Practicality of usage & $47 / 140$ & 33.57 & $43 / 76$ & 56.58 & 0.011 \\
\hline Unsuccessful previous usage & $60 / 138$ & 43.48 & $40 / 75$ & 53.33 & 0.404 \\
\hline Lack of supporting research data & $113 / 152$ & 74.32 & $44 / 79$ & 55.70 & 0.001 \\
\hline Lack of postgraduate training locally & $31 / 139$ & 22.30 & $51 / 79$ & 64.56 & 0.0005 \\
\hline Medico legal & $10 / 136$ & 7.35 & $12 / 71$ & 16.90 & 0.103 \\
\hline
\end{tabular}




\section{Parameter of judgment of treatment success with antimicrobial therapy}

The reduction in probing depth was judged to be the most frequent parameter for treatment success with antimicrobials by Specialist members $95.16 \%(\mathrm{n}=177)$ and the GDP $86.61 \%(\mathrm{n}=97)$, $\mathrm{p}=0.0005$. This was followed by an improved attachment level by the Specialist members $88.65 \%(n=164)$ which was higher than GDPs $49.73 \%(\mathrm{n}=92), \mathrm{p}=0.0005$. Both Specialist members $67.04 \%$ $(n=120)$ and GDP $60.91 \%(n=67)$ had similar opinions regarding the radiographic support improvement, $\mathrm{p}=0.361$. Microbial testing was the least parameter considered for treatment success in antimicrobial treatment (Specialist 10.34\%, GDP 7.84\%, $\mathrm{p}=0.282$ ) (Table 5).

\section{Further steps to be taken when antimicrobial therapy was judged to be unsuccessful}

The most common steps taken by the GDP when an antimicrobial was judged to be unsuccessful were 1) referral 94.29\% ( $\mathrm{n}=99)$, $\mathrm{p}=0.0005,2)$ extraction $91.18 \%(\mathrm{n}=93), \mathrm{p}=0.001$, and 3$)$ re root debridement $90 \%(\mathrm{n}=90), \mathrm{p}=0.922$. There were no differences in the number of Specialist members $57.14 \%(\mathrm{n}=92)$ and the GDP $62.63 \%$ $(n=62)$ who opted for re root debridement together with a systemic antimicrobial if the antimicrobial was judged to be unsuccessful, $\mathrm{p}=0.200$ (Table 6).

Table 5. Parameter for judgment of treatment success with antimicrobials in the main study population of the GDPs and Specialists in the United Kingdom.

\begin{tabular}{|c|c|c|c|c|c|}
\hline \multirow[t]{2}{*}{ Item } & \multicolumn{2}{|c|}{ Specialist Society/List } & \multicolumn{2}{|c|}{ GDP } & \multirow[t]{2}{*}{ P value } \\
\hline & Number+ & $(\%)$ & Number+ & $(\%)$ & \\
\hline Patient satisfied with result & $109 / 178$ & 61.24 & $80 / 107$ & 74.77 & 0.001 \\
\hline Reduction in bleeding & $169 / 184$ & 91.85 & $100 / 113$ & 88.50 & 0.054 \\
\hline Reduction in probing depth & $177 / 186$ & 95.16 & $97 / 112$ & 86.61 & 0.0005 \\
\hline Improved attachment level & $164 / 185$ & 88.65 & $92 / 185$ & 49.73 & 0.0005 \\
\hline Reduced tooth mobility & $129 / 181$ & 71.27 & $94 / 113$ & 83.19 & 0.012 \\
\hline $\begin{array}{l}\text { Improved radiographic bone } \\
\text { support }\end{array}$ & $120 / 179$ & 67.04 & $67 / 110$ & 60.91 & 0.361 \\
\hline Microbial testing & $18 / 174$ & 10.34 & $8 / 102$ & 7.84 & 0.282 \\
\hline
\end{tabular}

Table 6. Further steps when antimicrobial therapy was judged to be unsuccessful in the main study population of the GDPs and Specialists in the United Kingdom.

\begin{tabular}{|l|c|c|c|c|c|}
\hline \multirow{2}{*}{ Item } & \multicolumn{2}{|c|}{$\begin{array}{r}\text { Specialist Society/ } \\
\text { List }\end{array}$} & \multicolumn{2}{c|}{ GDP } & \multirow{2}{*}{ P value } \\
\cline { 2 - 6 } & Number & $(\%)$ & Number & (\%) & \multirow{2}{*}{0.0005} \\
\hline Referral & $57 / 170$ & 33.53 & $99 / 111$ & 89.20 & 0.338 \\
\hline Re root debridement & $154 / 172$ & 89.53 & $90 / 106$ & 84.91 & 0.019 \\
\hline $\begin{array}{l}\text { Re root debridement }+ \text { local delivery } \\
\text { antimicrobial }\end{array}$ & $70 / 162$ & 43.21 & $56 / 98$ & 57.14 & 0.103 \\
\hline $\begin{array}{l}\text { Re root debridement }+ \text { systemic } \\
\text { antimicrobial }\end{array}$ & $92 / 164$ & 56.10 & $62 / 105$ & 59.04 & 0.0005 \\
\hline Periodontal surgery & $165 / 182$ & 90.66 & $56 / 106$ & 52.83 & 0.005 \\
\hline Maintenance & $152 / 175$ & 86.86 & $80 / 101$ & 79.21 & 0.0005 \\
\hline Extraction & $153 / 176$ & 86.93 & $93 / 108$ & 86.11 & \\
\hline
\end{tabular}




\section{Associations between variables}

In the main study result section, the data analysis of the survey consisted of four parts which explored the frequency distribution of the study participants, demographic characteristics, periodontal management and the use of systemic and local antimicrobial.

1. The mean age of the sample was 44.8 years (range 23-70) and in relation to the years of graduation, the mean was 21.04 years (range 1-48). Regarding the gender, $36.63 \%$ of the population was male. The Specialist members significantly consisted of mainly females $41.27 \%(\mathrm{n}=78)$ whereas males were dominant in the GDP group $70.18 \% \%(\mathrm{n}=80)(\mathrm{p}=0.046)$.

2. In terms of root surface debridement performed for a quadrant, the majority of the Specialist population opted to spend more time on the procedure as compared to the GDP population ( $\mathrm{p}=0.0005)$. Specialists would also be more incline to routinely administer local anaesthetics for RSD (88.77\%).

3. The Specialist population treated more aggressive periodontitis patients than their GDP counterparts $94.14 \%(\mathrm{n}=177)$ and unresponsive sites $90.10 \%(\mathrm{n}=164)(\mathrm{p}=0.0005)$.

4. Regarding the use of systemic antimicrobials, the Specialist population would be more frequent to use systemic antimicrobial to treat aggressive periodontitis $(76.90 \%(\mathrm{n}=143), \mathrm{p}=0.003)$, and for unresponsive sites $(33.16 \%(n=64) \mathrm{p}=0.008$, missing value 55). Regarding local antimicrobials, a small number of Specialist members $2.22 \%(n=4)$ and GDP $4.80 \%(n=5)$ opted to prescribe this antimicrobial therapy for gingivitis respectively $(\mathrm{p}=0.005)$.

5. There was a significant lower number of the GDP population who prescribed antimicrobials in regenerative procedures $13.8 \%$ $(\mathrm{n}=14)$ or implant procedures $22.22 \%(\mathrm{n}=24)(\mathrm{p}=0.0005)$.

6. Regarding the perception of successful treatment with antimicrobials, the GDP $32.58 \%(\mathrm{n}=29)$ population opted to report that local antimicrobial therapy was often/routinely/very successful.

7. The Specialist population noted that it was easier (median 8) to decide to use systemic and local delivery antimicrobials in periodontal therapy ( $97.88 \%$ and $92.60 \%$ respectively, $\mathrm{p}=0.0005)$.

8. The most common reason for using local antimicrobial was because of its effectiveness; e.g., more effective than RSD alone as reported by the GDP population (65.85\%), and this was significantly different when compared to the Specialist population (51.16\%), $\mathrm{p}=0.050$. The most common reason for not using the type of antimicrobial was due to lack of supporting research data which was reported by the Specialist population $(74.32 \%, \mathrm{p}=0.001)$

9. Reduction in probing depth was judged to be the most frequent parameter for treatment success with antimicrobials by the Specialist population $(95.16 \%, \mathrm{p}=0.0005)$. Microbial testing was not considered to be a major variable for the treatment success in antimicrobial treatment, however no differences were noted between the groups (Specialist 10.34\%, GDP 7.84\%, $\mathrm{p}=0.282$ ).

10. The most common steps taken by the GDP population when antimicrobials were judged to be unsuccessful was referral to a
Specialist $89.20 \%, \mathrm{p}=0.0005$, whereas the Specialist was more inclined to perform periodontal surgery $90.66 \%, \mathrm{p}=0.0005$.

\section{Discussion}

One of the main observations from the present study related to the BSP members' demographic characteristics was the difference in the mean years from graduation namely 21.04 years (range 1-48 years). Regarding Specialist membership, a larger number of Specialists were members of a Specialist society ( $85.56 \%$ ), and $80 \%$ were BSP members. In the present study (in comparison with the previous results from Choudhury et al. [[8]), a significantly proportion of BSP/Specialist members indicated that they had attended a course or lecture on systemic $(89.73 \% v s .88 .3 \%)$ or local delivery antimicrobial delivery (76.50\% vs. $90.9 \%)$ in the treatment of periodontal disease. These figures also contrasted dramatically with the responses of GDPs from the present study where the attendance was significantly different to that of the Specialist colleagues. This observation would appear to support the conclusions by Palmer et al. [7] who reported that there were significant differences in the knowledge of the use of antibiotics from those practitioners who attended a postgraduate course. The response rate to the present study compared reasonably to the response rate from previous questionnaires studies [17-18]. The response rate for the questionnaires in the Choudhury et al. [8] was $73 \%$ which was higher than the response rate in the present study. There were however, sufficient data to compare the results from the two studies, although it should be noted that the periodontal categories used in the studies were different as the studies used a different classification system of periodontal disease. In retrospect it may have been useful to construct a simple algorithm to compare the results. A note of caution however should be noted in regard to the recruitment of the BSP members as there may be a degree of unconscious bias due to number of questionnaires handed out at a BSP meeting in Manchester by EAP (e.g., $91 \%$ rate from 100 questionnaires).

The present study noted that the use of systemic antibiotics by the participants generally were in accord with both previous and current recommendations $[2,12,16,19-20]$. The BSP members prescribed a more frequent use of antibiotics when treating more complex cases compared to GDPs. This practice may be due in part to the referral habits of the general practitioners who would refer the more advanced cases to Specialists (as recommended, e.g., BSP guidelines [based on the Basic Periodontal Examination]). One of the problems which may occur when referring patients with an advanced problem to a Specialist it may force the specialist to take a more aggressive treatment approach then if the patient had been referred at an earlier stage of the disease process [4].

No significant differences were noted between BSP members/ Specialists and GDPs in the use of an antimicrobial in the treatment of chronic periodontitis, although a relatively small number of participants prescribed an antibiotic for the treatment of gingivitis. Both groups however prescribed both systemic and local antibiotics/antimicrobials for the treatment of aggressive periodontitis and necrotising ulcerative gingivitis. BSP members/Specialists would on account of their higher frequency of treating aggressive periodontitis, routinely prescribe antibiotics/antimicrobials whereas necrotising ulcerative gingivitis 
was mainly treated by the GDPs. When comparing the results from the present study to the previous findings of Choudhury et al. [8] it was evident that BSP members/Specialists prescribed antimicrobials more frequently to treat aggressive periodontitis ( $76.90 \%$ vs. $52.7 \%)$ however the treatment of the unresponsive sites was lower in the present study (33.16\% vs. $49.6 \%$.). However, this apparent different may be as a result of the changes in the American Academy of Periodontology (AAP) classification rather than an actual change in the treatment of the conditions [16, 21]. A further observation between the two studies was that in the present study, in comparison to Choudhury et al. [8], the BSP Members/Specialists reported the limited use of antibiotics and antimicrobials in general. In the present study the BSP members/Specialists were more inclined to prescribe an antimicrobial for regenerative (45.60\%) or implant therapy procedures $(46.93 \%)$, although the frequency of prescription was relatively low. According to Heitz-Mayfield [2] this may be as a result of the limited data available on this practice which may subsequently lead to a degree of uncertainty by practitioners. This observation may also be true when considering guidelines and protocols for antibiotic prescribing regimens in dental implants procedures [11]. Regarding the use of a local antimicrobial, the results from the present study contrasted with the study by Choudhury et al. [8]. In general, a higher number of GDPs prescribed local antimicrobials as compared to the BSP members/Specialists although this was not statistically significant. This may be due to the perception by the GDPs that local antimicrobial therapy was more successful in resolving periodontal problems than BSP members. One observation that may be a concern was the observation that a relatively small number of GDPs (4.80\%) prescribed an antimicrobial for the treatment of gingivitis. There are several reasons for this, for example a misunderstanding of what the question was asking or a random mistake when completing the questionnaire. However, this may by supported by several investigators who reported that there are numerous prescriptions which were not in accord with the normal recommendations $[5,10]$.

One of the problems that was apparent from the results from the present study was that of decision making in the prescription and use of antibiotics/antimicrobials for the treatment of periodontal disease. This may be due to a number of reasons, for example the lack of understanding or confidence in the evidence of the efficacy of a particular drug, in comparison to the Choudhury et al. [8] study where some of the antimicrobials were relatively new to the market GDPs were more willing to prescribe and use antimicrobials as a result of their ease of use. It was also apparent as indicated previously that the general perception of GDP's was that the use of a local antimicrobial in treating periodontal disease would be successful. Furthermore, a higher number of GDPs choose to use a local antimicrobial as they considered it to be more effective than root surface debridement alone, and more cost effective than the other options in the questionnaire. Other reasons provided by the GDPs was that the use of a local antibiotic/ antimicrobial would avoid the need for additional surgical procedure and that the patient often requested the treatment as well as indicating that patients were generally satisfied with the treatment. Regarding the reasons for not using a local antimicrobial, cost would appear to a barrier for the GDPs, however the lack of postgraduate training locally was also a major factor, which was similar to the previous study by Choudhury et al. [8] (64.56\% vs. $47.6 \%)$. This was not surprising as it was evident from the significantly less numbers of GDPs who reported attending a lecture or course on local antimicrobial compared to BSP members/Specialists. The importance of updated one's knowledge on this topic may therefore be a factor in the decision-making process as to whether to use or not use antibiotics/antimicrobials. There was however a strange anomaly in the responses from the GDPs in that they noted that one of the reasons for not prescribing an antibiotic as the lack of supporting research data in the literature. In comparison to GDPs, the BSP members/Specialists reported that they spent more than 30 minutes for debridement under local anaesthetic as compared to the GDPs. This would suggest that mechanical treatment performed by the specialist may be more effective than that of the GDPs who may spend less time due to the constraint of the NHS service provision. A small percentage of the both specialist and GDPs in the present study reported that medico legal issues where a concern when considered whether to use/not use an antibiotic/antimicrobial. This would appear to be supported by the results of a questionnaire study by Lockhart et al. [22] who investigated the opinions and practices of infectious disease consultants regarding antimicrobial prophylaxis in dental procedures. $24 \%$ of the consultant population replied that the medico legal decision played a greater role than clinical data in the decisionmaking process.

When considering the success of an antimicrobial in the treatment of periodontal disease, both groups of participants indicated that the use of microbial testing was the least desirable variable to be taken into account when making a judgement, This observation was less than that reported in the Choudhury et al. [8] study (10.34\% vs. $83.3 \%)$. When considering which of the clinical parameters were routinely used in their practice. BSP members/Specialists reported significantly higher numbers of these variables, for example in reduction in bleeding level, reduction in probing depth, improved attachment level, and improved in radiographic bone support. It is therefore evident from the results of the present study that while both GDPs and BSP/Specialist members followed the current recommendations when prescribing and using systemic and local antimicrobial in periodontal therapy there is still a requirement for practitioners to be aware of more recent and updated universally accepted protocols and guidelines on the appropriate prescription and use of antibiotics/antimicrobials.

\section{Conclusion}

The results of the present study would indicate that there were limitations in both, the awareness, knowledge and prescription by dentists in the use of antibiotics/antimicrobials in the treatment of periodontal disease. Furthermore, there does not appear to be consistency in prescribing in terms of antibiotics/antimicrobials, dose or duration in root surface debridement, regenerative and implant procedures. In conclusion there is therefore a need for dentists to follow current guidelines when prescribing antibiotics/antimicrobials in order to avoid unnecessary prescriptions, antibiotic resistance and adverse drug reactions. 


\section{References}

1. Preshaw PM (2004) Antibiotics in the treatment of periodontitis. Dent Update 31: 448-450, 453-4, 456. [crossref]

2. Heitz-Mayfield LJ (2009) Systemic antibiotics in periodontal therapy. Aust Dent J 54: 96-101.

3. Herrera D, Matesanz P, Bascones-Martínez A, Sanz M (2012) Local and systemic antimicrobial therapy in periodontics. J Evid Based Dent Pract 12: 50-60. [crossref]

4. Preus HR, Albandar JM, Gjermo P (1992) Antibiotic prescribing practices among Norwegian dentists. Scand J Dent Res 100: 232-235. [crossref]

5. Palmer NO, Martin MV Pealing R; Ireland RS (2000) An Analysis of Antibiotic Prescriptions From General Dental Practitioners In England. $J$ Antimicrob Chemother 46: 1033-1035.

6. Palmer NO, Martin MV, Pealing R, Ireland RS (2001) Paediatric antibiotic prescribing by general dental practitioners in England. Int $J$ Paediatr Dent 11: 242-248. [crossref]

7. Palmer NO, Martin MV Pealing R; Ireland RS, Roy K, Smith A; Bagg J (2001) Antibiotic Prescribing Knowledge of National Health Service General Dental Practitioners in England And Scotland. J Antimicrob Chemother 47: 233-237.

8. Choudhury M, Needleman I, Gillam D; Moles DR (2001) Systemic and local antimicrobial use in periodontal therapy in England and Wales. $J$ Clin Periodontol 28: 833-839.

9. Mainjot A, D'Hoore W, Vanheusden A, Van Nieuwenhuysen JP (2009) Antibiotic prescribing in dental practice in Belgium. Int Endod J 42: 1112-1117. [crossref]

10. Dar-Odeh NS, Abu-Hammad OA, Al-Omiri MK, Khraisat AS, Shehabi AA (2010) Antibiotic prescribing practices by dentists: a review. Ther Clin Risk Manag 6: 301-306. [crossref]

11. Ireland RS, Palmer NO, Lindenmeyer A, Mills N (2012) An investigation of antibiotic prophylaxis in implant practice in the UK. Br Dent J 213: 14. [crossref]

12. Gillam DG; Turner W (2014) Antibiotics In The Treatment of Periodontal Disease: A Guide For The General Dental Practitioner. Prim Dent J 3: 43-47.

13. SDCEP Scottish Drug Prescribing for Dentistry Dental Clinical Guidance 3rd Edition Update June 2017. http://www.sdcep.org.uk/wp-content/uploads/2017/06/ SDCEP-Drug-Prescribing-Ed-3-Update-June-2017.pdf

14. Public Health England Dental antimicrobial stewardship: toolkit. Resources to help primary care practitioners promote the appropriate use of antibiotics in dental care. Published 9th November 2016; Updated 16th July 2019. https://www.gov.uk/ guidance/dental-antimicrobial-stewardship-toolkit.

15. Armitage GC (1999) Development of a classification system for periodontal diseases and conditions. Ann Periodontol 4: 1-6. [crossref]

16. Armitage GC (2004) Periodontal diagnoses and classification of periodontal diseases. Periodontol 2000 34: 9-21. [crossref]

17. Gillam DG, Seo HS, Bulman JS; Newman HN (1999) Perceptions of dentine hypersensitivity in a general practice population. J Oral Rehabil 26: 710-714.

18. Gillam DG, Seo HS, Newman HN; Bulman JS (2001) Comparison of dentine hypersensitivity in selected occidental and oriental populations. J Oral Rehabil 28: $20-25$.

19. Palmer NA (2003) Revisiting the role of dentists in prescribing antibiotics. Dent Update 30: 570-574. [crossref]

20. Dumitrescu AL (2011) Chapter 3 The Systematic Use of Antibiotics in Periodontal Therapy. In Antibiotics and Antiseptics in Periodontal Therapy. Ed Dumitrescu AL. Springer-Verlag Berlin Heidelberg 2011 Pg No: 79-169.

21. Wiebe CB, Putnins EE (2000) The periodontal disease classification system of the American Academy of Periodontology--an update. J Can Dent Assoc 66: 594-597. [crossref]

22. Lockhart PB, Brennan MT, Fox PC, Norton HJ, Jernigan DB, Strausbaugh LJ (2002) Decision-making on the use of antimicrobial prophylaxis for dental procedures: a survey of infectious disease consultants and review. Clin Infect Dis 34: 1621-1626.

\section{Citation:}

Padtong EA, Turner W, David-Gilla n( 020) UK Specialists' and GDPs' Use of Systemic and Local Antimicrobial Administration in Periodontal Therapy: A Questionnaire Study. J Dent Maxillofacial Res Volume 3(1): 1-9. 